\title{
Plastic surgery on the upper eye-lid after enucleation of the eye
}

\author{
OTTO RIEBEL
}

From the Department of Ophthalmology, Medical Faculty Hospital, University $\mathscr{F} E P$ Brno, Czechoslovakia

The removal of an eye not only means loss of sight to the patient, but it produces a cosmetic blemish.

The principal cosmetic imperfections are:

I. Restricted movement of the prosthesis.

2. An obvious deep groove in the upper eye-lid.

Restriction of movement of the prosthesis can be partially overcome by the use of various types of implant (Hughes, 1948; Jendralski, 1941; Knobloch, I940; Vanýsek, I95 I).

Address for reprints: Professor MUDr. Otto Riebel, Head of Department of Ophthalmology, Medical Faculty Hospital, University JEP, Brno, Czechoslovakia
Treatment of the deep groove in the upper lid which is a constant operative result of enucleation in the absence of a buried implant, is the subject of this clinical note.

\section{Operation procedure}

The basis of the operation is to separate the middle third of the tendon of the upper lid levator from the tarsal plate and stitch this prepared strip to the periosteum of the upper edge of the orbit (Fig. I). The aim of the operation is the return of the tarsal plate and the upper lid to its preoperative position (Figs 2 and 3 ).

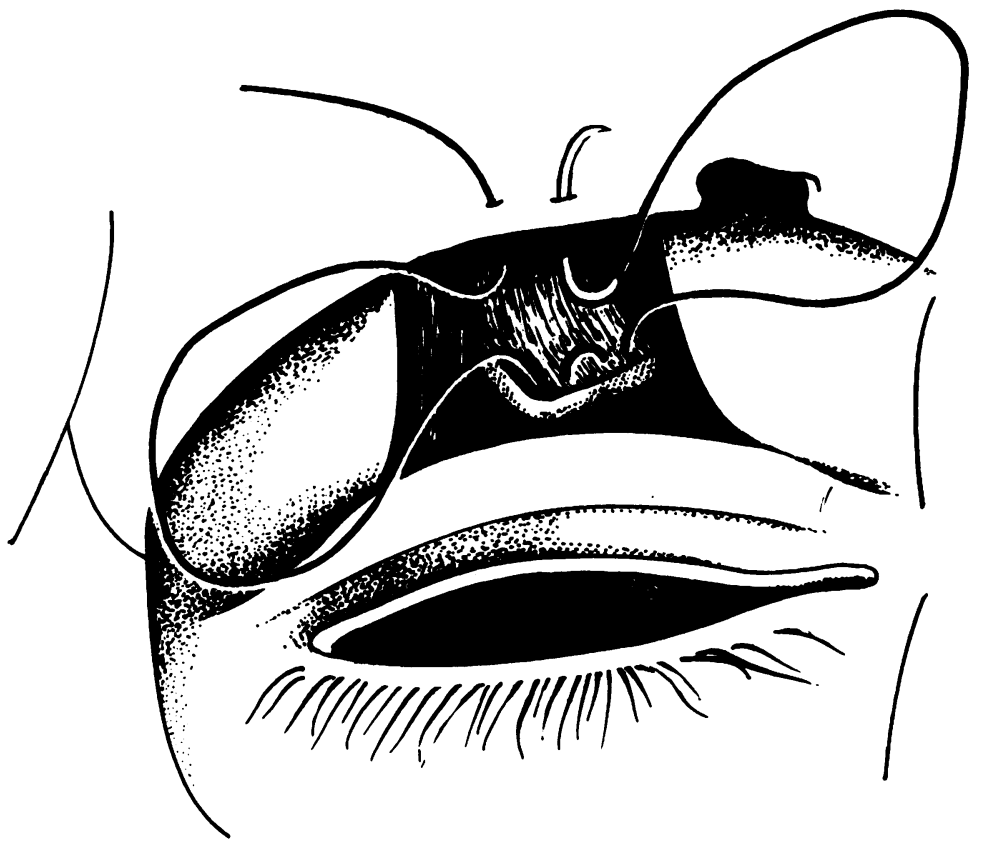

FIG. I After exposing the tendon of the upper lid levator a stitch is put into the middle third of the tendon. This part of the muscle is clipped away from the tarsal plate and with help of lengthwise incisions a muscle lobe is created and fixed to the periosteum of the orbital edge 


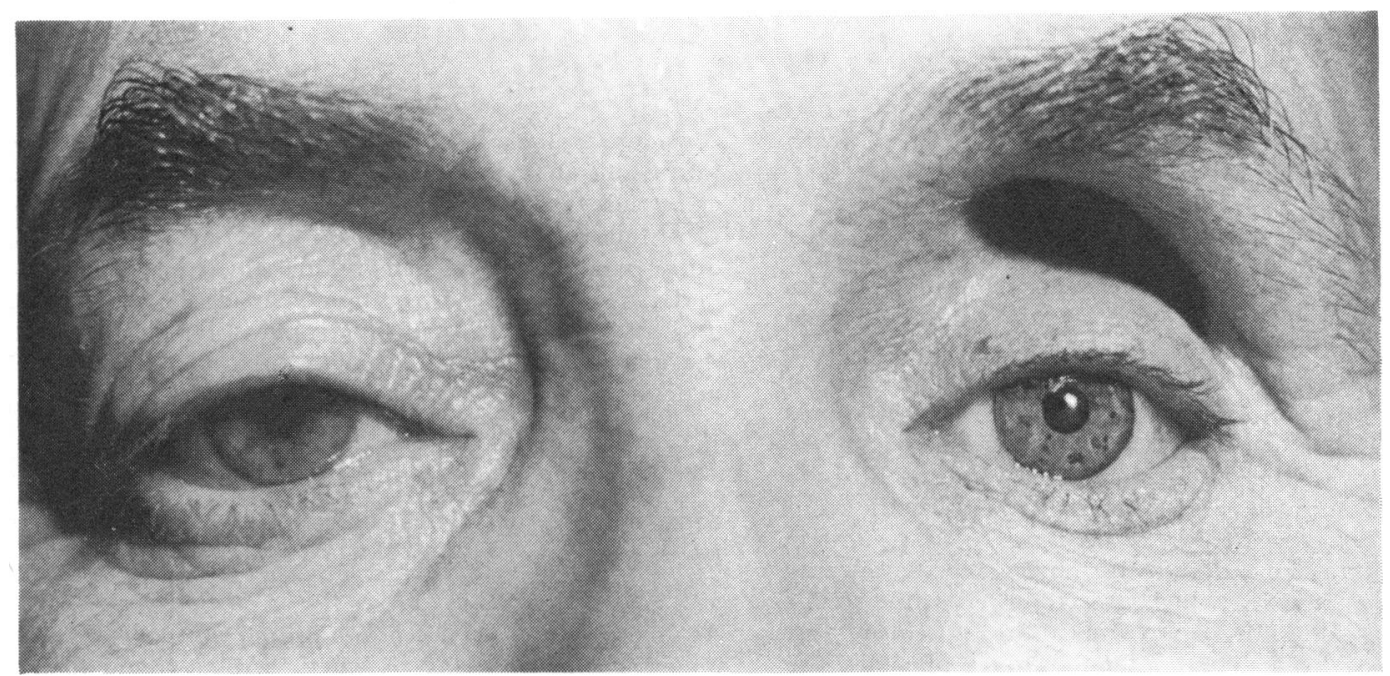

FIG. 2 The preoperative state: deep groove of the upper lid after enucleation of left eye

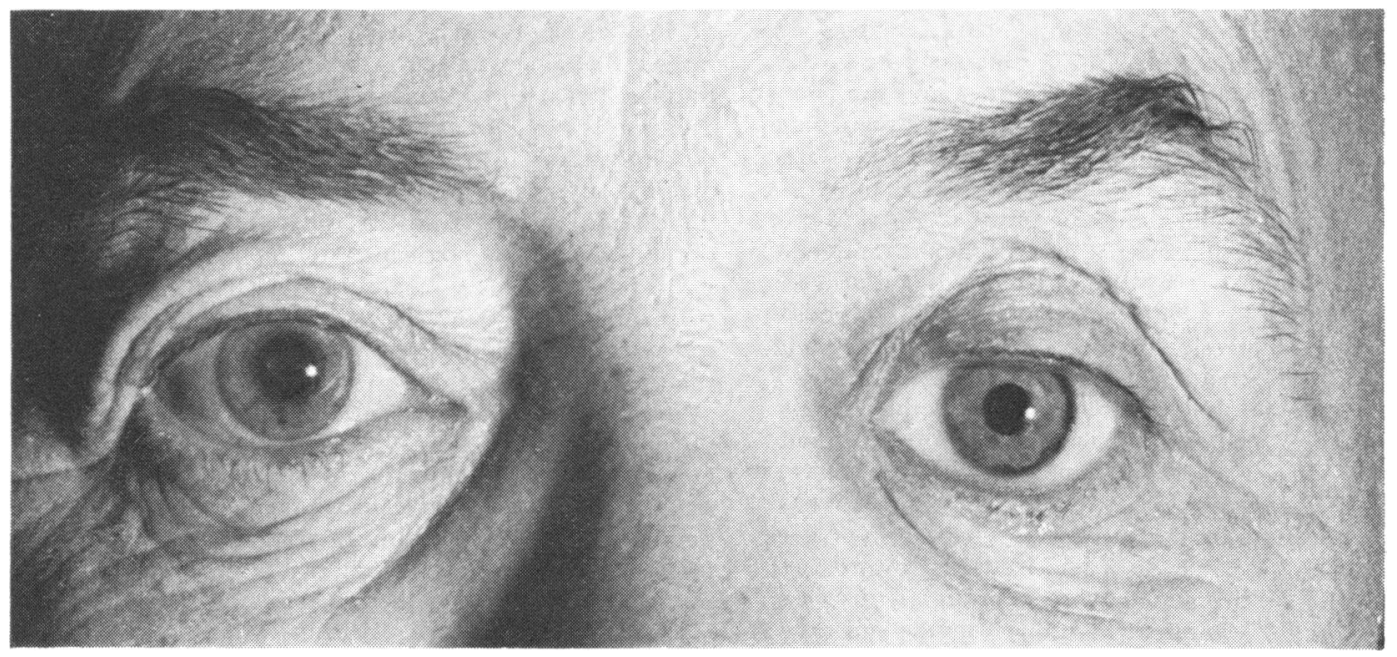

FIG. 3 The state after plastic surgery. The upper lid has returned to its original position and the deep groove has disappeared

\section{References}

Hughes, w. L. (1948) Amer. F. Ophthal., 31, 303

JENDRALSKI, F. (1941) Klin. Mbl. Augenheilk., 106, 279

KNOBLOCH, R. (1940) Cas. Lék. ces., 79, 652

vANÝSEK, J. (195I) Čs. Oftal., 7, 3 I9 